\title{
Fibrin sealant repair of a double-necked femoral pseudoaneurysm
}

(iD) Ronald Flumignan ${ }^{1}$ Henrique Guedes Neto ${ }^{1}$

Samuel Araujo

Yuri Di Giulio ${ }^{1}$

Camila Porta ${ }^{1}$

Jorge Amorim ${ }^{1}$

Luis Nakano ${ }^{1}$

1. Universidade Federal de São Paulo, Division of Vascular Endovascular Surgery, Department of Surgery, São Paulo, SP, Brasil

\section{SUMMARY}

Pseudoaneurysms are rare, but femoral artery false aneurysms have increased in recent decades. They are related to endovascular procedures performed on patients with increased risk for this complication. Pseudoaneurysms generally present with only one neck. This paper describes a femoral artery pseudoaneurysm with two necks that occurred after an endovascular procedure and was successfully treated by duplex-guided fibrin sealant. Pseudoaneurysms are rare, but femoral artery pseudoaneurysms have increased with a discrepant incidence reported from $0.5 \%$ to almost $4 \%$, mainly related to the increase of endovascular procedures in recent decades. The double-necked pseudoaneurysm identification was of utmost importance to guide the clinical decision-making and allowed good outcomes for the patient.

KEYWORDS: Aneurysm, False. Fibrin Tissue Adhesive. Ultrasonography, Interventional. Vascular Diseases.

\section{INTRODUCTION}

Pseudoaneurysms are an uncommon clinical entity, generally arising after trauma or surgical procedures. However, pseudoaneurysms may affect up to $3 \%$ of vascular access for endovascular procedures, mainly in patients that present risk factors for local complication of the procedure ${ }^{1,2}$. Most of these pseudoaneurysms have only one neck and are first-line treated with compression (blind or ultrasound-guided) $)^{3}$. The presence of a second neck could contribute to the failure of this initial treatment by the addition- al flow in the pseudoaneurysm and also contribute to complications such as deep venous thrombosis, because it requires more intense or prolonged compressions. Ultrasound-guided thrombin injection is reserved for those in whom the compression procedure fails ${ }^{3}$. Even in the treatment with thrombin injection, the two-neck pseudoaneurysm presents additional challenges. Flow in the second neck may also be an additional pathway for distal embolization (main complication of this treatment). The physi- 
cian who performs those procedures must be alert to identify the patients at risk of complications, predict complications as compression failure, and treat them as soon as they arise with the best available alternative $^{2-5}$. After physical examination, duplex ultrasound remains the cornerstone imaging test for better clinical decision-making in the treatment of femoral pseudoaneurysm, especially in the detection of morphological alterations that affect clinical outcomes, such as the presence of more than one neck ${ }^{2}$. Following the CARE statements, a topical case is described that exemplifies the importance of detailed pre-treatment evaluation ${ }^{6,7}$.

\section{CASE}

A 32-year-old woman, body mass index of $33 \mathrm{~kg} /$ $\mathrm{m}^{2}$, who presented a non-sustained ventricular tachycardia during pregnancy, was submitted to an endovascular cardiac ablation 40 days after delivery. The endovascular procedure was performed with difficulty due to the patient's obesity. Five puncture attempts were required and a $5 \mathrm{~F}$ introducer was used. Six hours after the end of the endovascular procedure, she was evolved with a pulsatile mass at the puncture site in the right groin, associated with pain and paraesthesia of the right lower inferior limb. Colour Doppler ultrasonography (9 MHz linear transducer, Logic P6, GE healthcare, Wauwatosa, USA) was performed and showed signs of a pseudoaneurysm (Ying-Yang sign) of $1.7 \times 2.6 \times 2.3 \mathrm{~cm}(10 \mathrm{ml})$ localised between the femoral and deep femoral arteries (Figure 1). The false aneurysm had two necks, one at the femoral artery and the other at the deep femoral artery, with a length of $0.55 \mathrm{~cm}$ and $0.33 \mathrm{~cm}$, and a width of $0.24 \mathrm{~cm}$ and 0.44 $\mathrm{cm}$, respectively (Figure 1).

Firstly, following the diagnosis and pain control with opioids, ultrasound-guided compression was performed on the right groin during two 40-minute attempts. Since the false aneurysm remained at the one-hour duplex control, an ultrasound-guided fibrin sealant injection of $2 \mathrm{~mL}$ was performed under local anaesthesia. The fibrin sealant was a commercial tissue adhesive containing fibrinogen and thrombin (Tisseel Lyo ${ }^{\circledR}$, Baxter AG, Vienna, Austria), and it was injected into the sac of the pseudoaneurysm avoiding the injection in the necks. The immediate control with duplex ultrasound revealed an almost complete
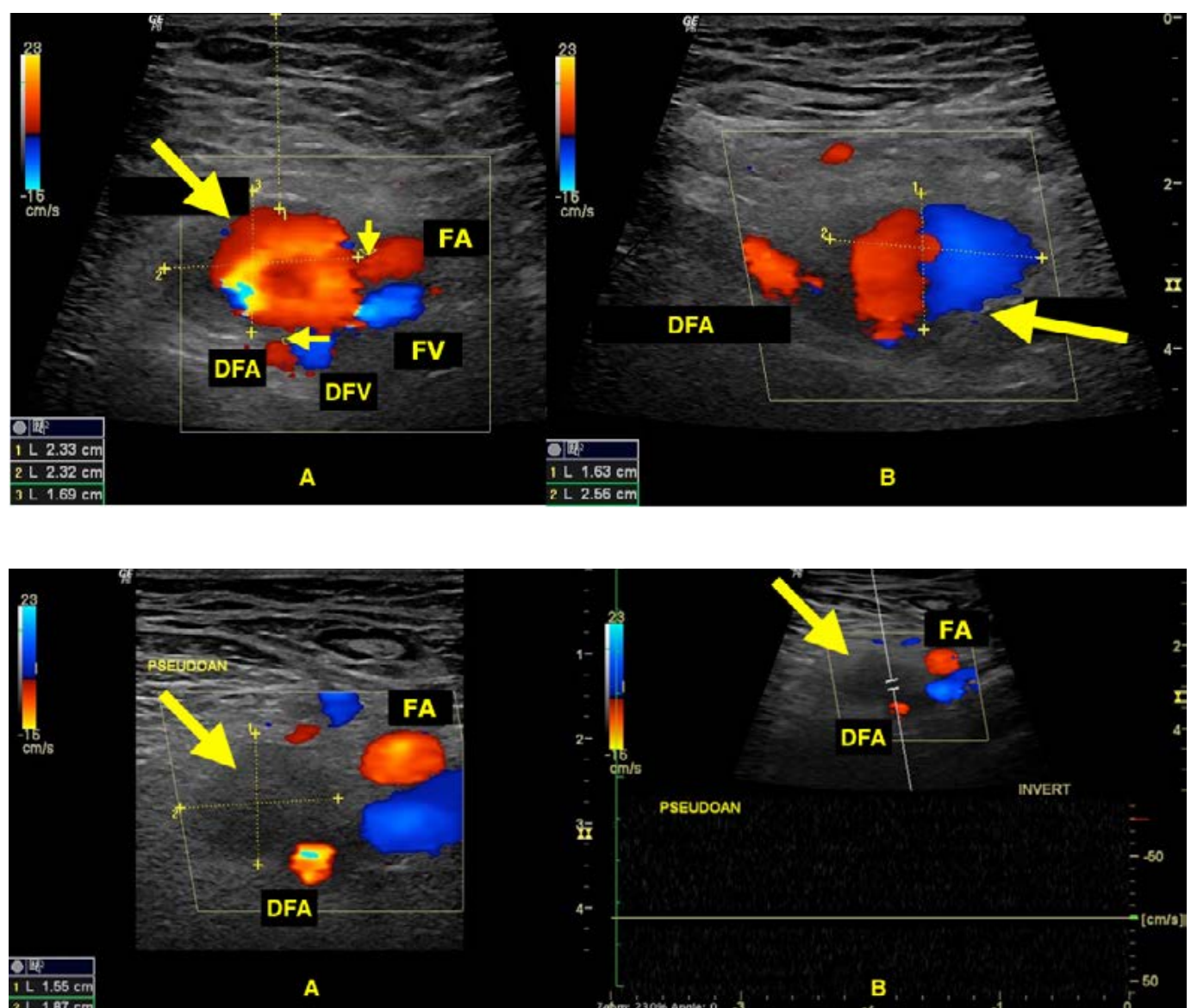

\section{FIGURE 1}

Colour Doppler ultrasonography before fibrin sealant repair. A: transversal section of groin vessels; big arrow = pseudoaneurysm; small arrows $=$ necks. $\mathrm{B}$ : longitudinal section of groin vessels; big arrow = Ying-Yang sign inside the pseudoaneurysm, D FA = d e e $p$ femoral artery, $D F V=$ d e e $p$ femoral vein, $F A=$ femoral artery and $F V=$ femoral vein .

\section{FIGURE 2}

Colour Doppler ultrasonography after fibrin sealant repair at 24-h control. A: transversal section of groin vessels; big arrow = o c cl u d e d pseudoaneurysm. B: transversal section of groinvesselswith duplex ultrasound; big arrow $=$ occluded pseudoaneurysm, D F A = de e p femoral artery and FA = $\mathrm{fe} \mathrm{m}$ o r a l artery. 
occlusion of the pseudoaneurysm and no sign of distal embolization. The 24-h duplex control showed a complete occlusion of the pseudoaneurysm, without colour imaging and without any waveform inside the lesion (Figure 2). All distal arteries of the right lower limb were maintained previously. One month after the procedure, under no indication of pain or paraesthesia, another duplex control confirmed the right femoral artery false aneurysm occlusion without any distal embolization, and no sign of haematoma.

\section{DISCUSSION}

Pseudoaneurysms are rare, but femoral artery pseudoaneurysms have increased with a discrepant incidence reported from $0.5 \%$ to almost $4 \%$, mainly related to the increase of endovascular procedures in recent decades ${ }^{1,8,9}$. One of the main purpose of endovascular procedures is reducing surgical risks and complications, such as pseudoaneurysm at the vascular access site. Pseudoaneurysms at the vascular access site are associated with several risk factors, including advanced age ( $>75$ years old), female gender, elevated body mass index, degree of arterial calcification, platelet depletion, the use of anticoagulants, the urgency of the procedure, the site of arterial cannulation, and the use of combined arterial and venous access ${ }^{2,5,10}$. The presence of a second neck is a rare finding in femoral pseudoaneurysms but should be included in the list of risk factors for complications, especially since it can contribute to the failure of initial compression, to thrombosis and to distal embolization. Further care should be taken, as in this case, to avoid the necks of the pseudoaneurysm in the injection of fibrin sealant in order to avoid arterial thrombosis or distal embolization.

Patient physical examination with the presence of a pulsatile mass at the groin region or the presence of a non-pulsatile inguinal mass and superficial haematoma must lead the physician to the pseudoaneurysm diagnosis hypothesis ${ }^{10}$. Diagnostic confirmation is achieved by the use of duplex ultrasound to determine the presence of a vessel defect, its measures, the presence of hypo-echoic collection, and the colour and spectral modes to make the distinction between a haematoma and a pseudoaneurysm. Systematic reviews of randomised controlled trials suggest that femoral artery pseudoaneurysms must be treated firstly by compression (blind or ultrasound-guided) and after an unsuccessful attempt, duplex-guided thrombin injection seems to be the best choice ${ }^{3}$. This report describes a case of femoral artery pseudoaneurysm with two necks after an endovascular procedure in an obese and female patient that was successfully treated by duplex-guided fibrin sealant. The double-necked pseudoaneurysm identification was of utmost importance to guide the clinical decision-making and allowed good outcomes for the patient.

\section{Declaration of conflicting interests}

The authors declare no potential conflicts of interest with respect to the research, authorship, and/or publication of this article.

\section{Ethical approval}

Our institution does not require ethical approval for reporting individual cases or case series until the time of manuscript submission.

\section{Funding}

The authors received no financial support for the research, authorship, and/or publication of this article.

\section{Informed consent}

Written informed consent was obtained from the patient for her anonymised information to be published in this article.

\section{Contributors}

RLF, HJGN, STA, JEA, LCN - study design, data collection, data analysis and writing. YLG, CGP - data collection and writing

\section{RESUMO}

Os pseudoaneurismas são raros, mas os aneurismas falsos da artéria femoral aumentaram nas últimas décadas. Eles estão relacionados aos procedimentos endovasculares realizados em pacientes com risco aumentado para esta complicação. Os pseudoaneurismas geralmente apresentam apenas um colo. Este artigo descreve um pseudoaneurisma da artéria femoral com dois colos que ocorreu após um procedimento endovascular e foi tratado com sucesso por selante de fibrina guiado por duplex. Os pseudoaneurismas são raros, mas os pseudoaneurismas da artéria femoral aumentaram com uma incidência discrepante relatada de 0,5\% a 4\%, principalmente relacionada ao aumento dos procedimentos endovasculares nas últimas décadas. A identificação do pseudoaneurisma de colo duplo foi de extrema importância para orientar a tomada de decisão clínica e permitiu bons resultados para o paciente.

PALAVRAS-CHAVE: Falso aneurisma. Adesivo tecidual de fibrina. Ultrassonografia de intervenção. Doenças vasculares. 


\section{REFERENCES}

1. Hirano $Y$, Ikuta $S$, Uehara $H$, Nakamura $H$, Taniguchi $M$, Kimura A, et al. Diagnosis of vascular complications at the puncture site after cardiac catheterization. J Cardiol. 2004;43(6):259-65.

2. Stone PA, Campbell JE, AbuRahma AF. Femoral pseudoaneurysms after percutaneous access. J Vasc Surg. 2014;60(5):1359-66.

3. Tisi PV, Callam MJ. Treatment for femoral pseudoaneurysms. Cochrane Database Syst Rev. 2013;(11):CD004981.

4. Yoo T, Starr JE, Go MR, Vaccaro PS, Satiani B, Haurani MJ. Ultrasound-guided thrombin injection is a safe and effective treatment for femoral artery pseudoaneurysm in the morbidly obese. Vasc Endovascular Surg. 2017;51(6):368-72.

5. Ocke Reis PE, Roever L, Ocke Reis IF, Azambuja Fontes F, Rotolo Nascimento M, Nunes dos Santos L, et al. Endovascular stent grafting of a deep femoral artery pseudoaneurysm. EJVES Short Rep. 2016;33:5-8.
6. Gagnier J), Kienle G, Altman DG, Moher D, Sox H, Riley D; CARE Group. The CARE guidelines: consensus-based clinical case reporting guideline development. BMJ Case Rep. 2013;2013. pii: bcr2013201554.

7. Riley DS, Barber MS, Kienle GS, Aronson IK, von Schoen-Angerer T, Tugwell $P$, et al. CARE guidelines for case reports: explanation and elaboration document. J Clin Epidemiol. 2017;89:218-35.

8. Standard for diagnostic arteriography in adults. Standards of Practice Committee of the Society of Cardiovascular and Interventional Radiology. I Vasc Interv Radiol. 1993;4(3):385-95.

9. Moll R, Habscheid W, Landwehr P. The frequency of false aneurysms of the femoral artery following heart catheterization and PTA (percutaneous transluminal angioplasty). Rofo. 1991;154(1):23-7.

10. Mlekusch W, Haumer M, Mlekusch I, Dick P, Steiner-Boeker S, Bartok A, et al. Prediction of iatrogenic pseudoaneurysm after percutaneous endovascular procedures. Radiology. 2006;240(2):597-602. 